\title{
Investigation of Warp and Weft Knitted Fabric Acoustic Structures Derived from Garment Waste
}

\author{
Alhayat Getu Temesgen ${ }^{1 *}, 0$ mprakash Sahu ${ }^{2 *}$ \\ ${ }^{1}$ Department of Textile Engineering, Institute of Technology, Wollo University, Kombolcha, Ethiopia \\ ${ }^{2}$ Department of Chemical Engineering, UIE Chandigarh University, Mohali, Punjab, India \\ Email: *ops0121@gmail.com, *mottaget@gmail.com
}

How to cite this paper: Temesgen, A.G. and Sahu, O. (2022) Investigation of Warp and Weft Knitted Fabric Acoustic Structures Derived from Garment Waste. Journal of Textile Science and Technology, $\mathbf{8}$, 35-42.

https://doi.org/10.4236/jtst.2022.81004

Received: December 28, 2021

Accepted: February 7, 2022

Published: February 10, 2022

Copyright $\odot 2022$ by author(s) and Scientific Research Publishing Inc. This work is licensed under the Creative Commons Attribution International License (CC BY 4.0).

http://creativecommons.org/licenses/by/4.0/

\begin{abstract}
The mechanical performance of knitted fabric was significantly affected by loop density and geometries. Knitted fabric composites occupy a special position in the field of engineering materials because of their easy to form complex components and high impact energy absorption. But Knitted fabric composites have low in-plane tensile strength because the yarns are in a loop structure in the materials. Sound insulation requirements in automobiles, manufacturing environments, and equipment, generating higher sound pressure drive the need to develop more efficient and economical ways of producing sound absorption materials. The knitted fabric based acoustic materials were produced from cut wastes from different garment industries for their sound absorption property test as per the method described in ASTM E 1050. The acoustic performance of knitted fabrics was measured by independent tube methods for sound waves of $1000-6000 \mathrm{~Hz}$. It is observed that the knitted fabrics acoustic materials prepared from waste materials showed high sound absorption than woven fabrics made from the same synthetic fibers. Moreover, the test revealed that blended knitted fabric had a better sound absorption property.
\end{abstract}

\section{Keywords}

Knitted fabric, Acoustic Properties, Independent Tube, Garment Waste

\section{Introduction}

Knitted fabric is the form of fabric manufacturing by interloping of a single yarn in the horizontal as well as vertical directions by using a knitting machine. Based on the inter looping direction of the looped structure, knitted fabrics are clas- 
sified as warp and weft knitted fabric as shown in Figure 1(a) and Figure 1(b) [1] [2] [3] [4] [5]. Weft knitting is a method of forming a fabric by knitting means in which the loops are made in a horizontal way from a single yarn and intermeshing of loops takes place in a circular or flat form on a course-wise basis [6] [7] [8]. While Warp knitting is a method of forming a fabric by knitting means in which the loops are made in a vertical way along the length of the fabric from each warp yarn and intermeshing of loops takes place in a flat form on a length-wise basis. So Warp knitting is characterized by the structural threads of the fabric running along the length of the fabrics [9] [10] [11]. According to Wadje 2009 report, the mechanical performance of knitted fabric was significantly affected by loop density and geometries as shown in Table 1. Until recent time, knitted fabrics have been not effectively utilized as composite reinforcing materials. Similarly, Gommers in 1998, Pamuk and Çeken in 2008 reported that most manufactures focused on using woven and braiding textile materials in composite fabrications. There are two basic reasons why knitted fabrics did not attract researchers and manufacturers for a long period of time is that knitted fabric reinforced structures cannot carry heavy loads (lose their structure) and the required level of fiber contents is not achieved in the composite structures. Gommers in 1998 reported that for the last 10 years, these two assumptions are disproved by various research work and investigators. Knitted fabric manufacturing is one of the most versatile techniques for the textile fabrics fabrication processes. This is one of the most desirable properties for textile materials used as reinforcing structures. For knitted fabric reinforced composite, the knitted fabric structures are selected by three major criteria, the first criteria are knitted structure deformations, the second criteria is that physical and mechanical properties of the knitted fabrics and the third selection criteria are the curl nature of knitted structure. Composite materials reinforced by knitted fabrics have special properties and advantages: 1) Knitted fabrics having super drapability and deformation properties help for the formation of complex and interacted shapes without creating folds. 2) Advanced knitting machines are used for manufacturing the desired shapes. 3) Their versatility. These major properties have played a significant role in the overall properties of composite materials reinforced by knitted fabrics, to have better impact resistance, flexibility, excellent inter-laminar performance, lower fabrication periods and high fabrication rates [12] [13] [14].

A recently large amount of small scale garment industries has been generated. These garment industries are generated a large amount of cut pieces of cloths into the environments, are commonly called garment wastes. These huge amounts of waste materials had their own effect on global warming. Using wastes as raw materials have both economic and environmental advantages. Noise is a form of air pollution and like other forms of pollution, it affects the quality of the life [15] [16]. Noise accompanies distraction in the working place with consequent reduction in production, efficiency, accuracy and safety. The acoustic properties 
of knitted fabric structures were influenced by several factors such as porosity of the yarn, orientation, distribution, quality of waste garment, volume of fiber fraction and the type of knitted fabric manufacturing (warp or weft knitting) used for sound absorption [17] [18] [19] [20]. This research work was focused on the effect of type of knitting mechanism and utilization of garment waste materials to generate additional income and also reduced industrial waste materials.

\section{Materials and Methods}

\subsection{Materials}

Warp and weft types of knitted fabrics were collected from different garment factories. Weft and warp kind of knitted fabric structures are used as reinforcing materials as shown in Table 1. Inter looping direction of the looped structure, knitted fabrics are classified as warp and weft knitted fabric as shown in Figure 1(a) and Figure 1(b). The knitted fabric structures were interloped from different fibers such as natural fibers, manmade fibers and blended fibers. Knitted fabric wastes have a significate effect on the acoustic properties due to their high loop length and these loops would hold the spikes while opening.

\subsection{Method}

The collected knitted waste fabrics were opened and the acoustic structure was

Table 1. Characteristics of weft and warp knitting fabric.

\begin{tabular}{ll}
\hline Weft knitted fabrics & Warp knitted fabrics \\
\hline Threads are run in vertical direction & Threads are runs in horizontal direction \\
Highly elongation & $\begin{array}{l}\text { Less elongation } \\
\text { One thread is required for each needle } \\
\text { Required one yarn }\end{array}$ \\
The course is equal to the pattern & Higher course is needed for a pattern \\
Elongated in width direction & Elongated lengthwise \\
Appropriate for thin fabric production & Appropriate for fabrication of course materials \\
Has a Problem of shrinkage & Good shrinkage resistance \\
Thread is feed from a single cone & Yarns are feed from beams \\
\hline
\end{tabular}

(a)

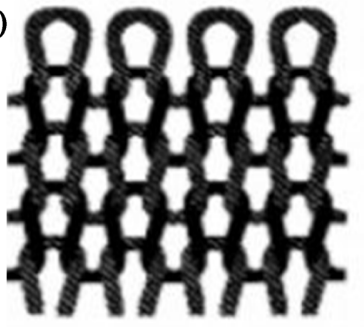

Weft Knit (b)

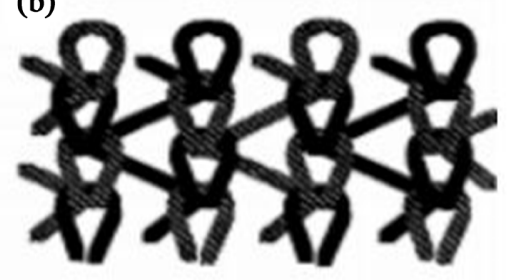

Warp Knit

Figure 1. Type of knitted fabric structure. 
processed through sequence of mechanism by the principles of mechanical web laying technique and aero dynamic principle and chemical bonding (like nonwoven manufacturing techniques) as shown in Figure 2. The impedance tube method was used to determine sound absorption coefficients of the knitted fabric reinforced composite structures as shown in Figure 3. ASTM 1050 standard was used for these studies. The specimens were prepared based on the standard and the test was conducted. The average test result was used for test results interpretation.

Impedance Tube $(50 \mathrm{~Hz}-6000 \mathrm{~Hz})$ consists of:

- A $100 \mathrm{~mm}$ diameter tube (large tube);

- A $29 \mathrm{~mm}$ diameter tube (small tube);

- Sample holders (29 and $100 \mathrm{~mm}$ );

- Extension tubes (29 and $100 \mathrm{~mm}$ ).

\section{Results and Decisions}

\subsection{Acoustic Properties of Warp Knitted Fabric from Garment Waste}

The test result revealed as Figure 4 shown below was summarized as the samples of $30 \mathrm{~mm}$ diameter of retrieved weft knitted fabric produced by chemical bonded mechanism with large tube impedance tube in the frequency range of $1000 \mathrm{~Hz}$ to $6000 \mathrm{~Hz}$. The non-laminated sheet reaches 0.96 of sound absorption at the frequency of $4000 \mathrm{~Hz}$, which is porous natured, the laminated sample shows 0.96 of sound absorption at the same frequency due to blocking of pores,

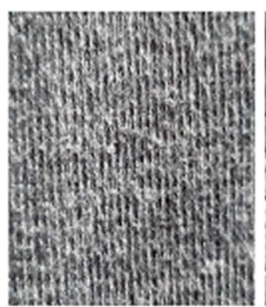

(a)

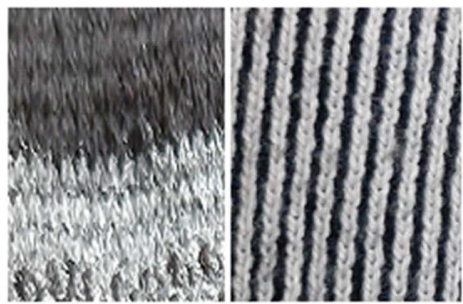

(b)

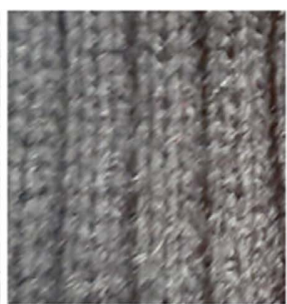

(d)

Figure 2. Specimens used for acoustic test (a) nature fiber, (b \& c) manmade fibers and (c) blended fibers.

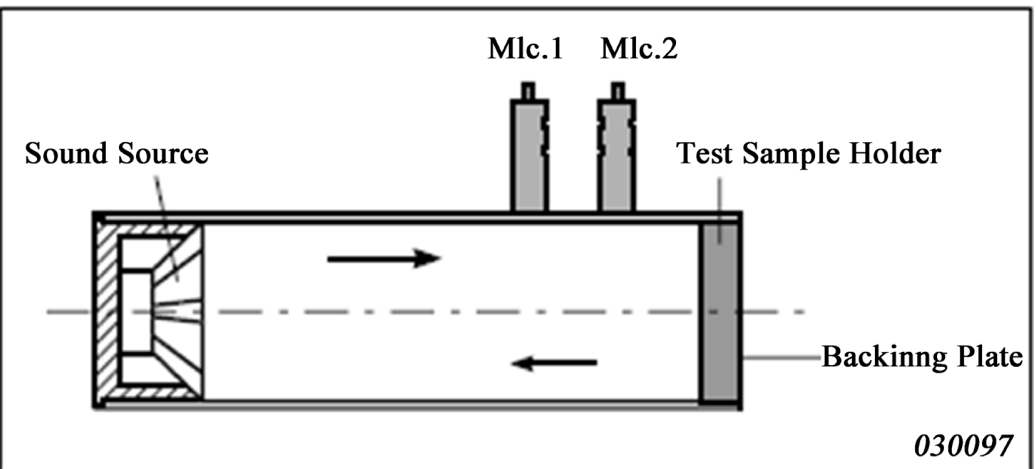

Figure 3. Acoustic properties test with impedance tube. 


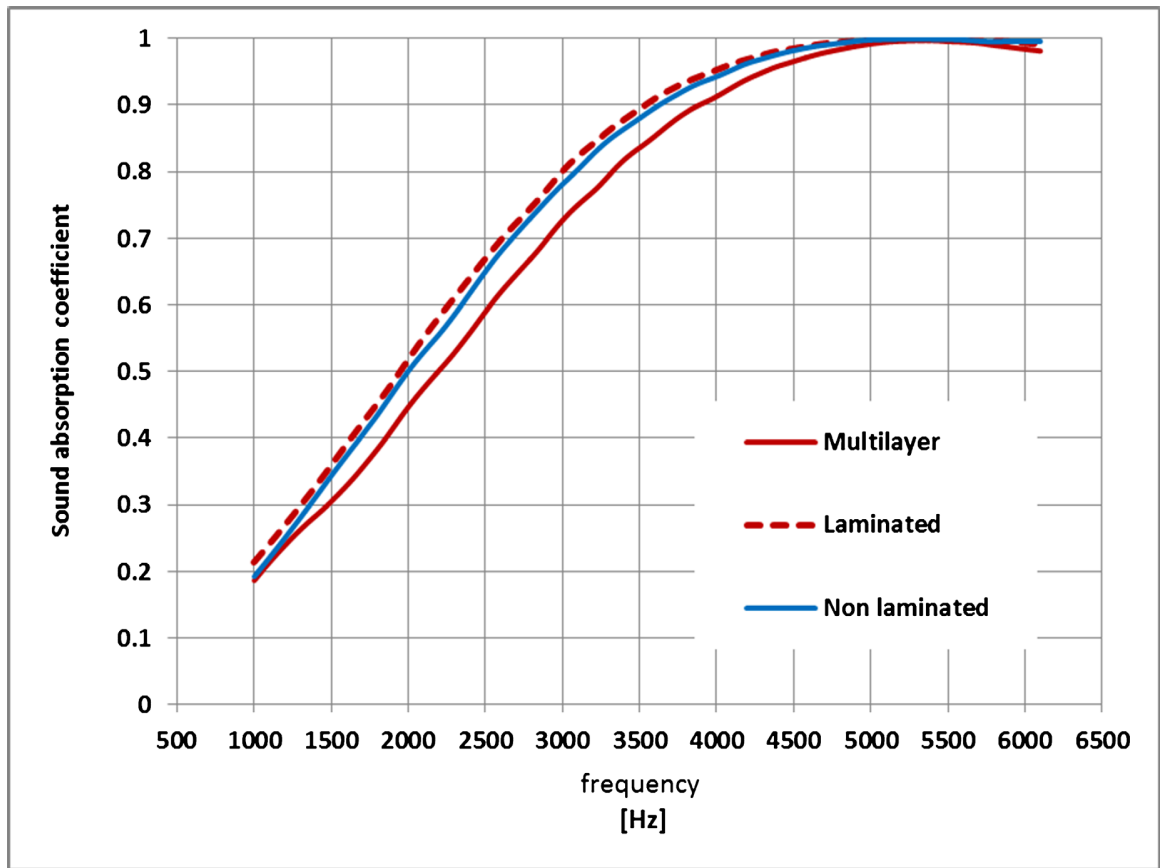

Figure 4. Non laminated, laminated and multilayer weft knitted fabric sound absorption properties.

whereas the multilayer samples shown due to calendar compression of the sheet reach the sound absorption at the level of $0.91 \%$.

\subsection{Acoustic Properties of Weft Knitted Fabric}

The needle punched Warp knitted fabric samples produced from blended three different fibers, these are Enset, jute and cotton with $30 \mathrm{~mm}$ diameter and the sample were prepared by the needle punched fabric manufacturing mechanism like nonwoven. The test result was summarized in Figure 5. The coir/jute [50/50] and the coir/enset [50/50] shows near $40 \%$ in sound absorption, rather the jute/ enset with a ratio of 50/50 had sound absorption coefficient values of $0.92,0.86$ and 0.63 at the frequency of $3000 \mathrm{~Hz}$ respectively.

\subsection{Sound Absorption Properties of Garment Waste from Knitted Fabric Made of Viscose, Wool, Cotton and Their Blend}

The four knitted fabric specimens made from cotton, wool, viscose and their blend having $30 \mathrm{~mm}$ diameter where tested for their acoustic properties as shown in Figure 6. The test results revealed that all the specimens had nearly similar sound absorption coefficient values at lower, medium and higher frequency regions, the maximum sound absorption coefficient values were recorded 0.98 at the frequency of $5500 \mathrm{~Hz}$.

\section{Conclusion}

The test results revealed that the acoustic materials made from knitted fabric produced from short fiber yarns such as cotton, wool, jute, enset as well as continuous 


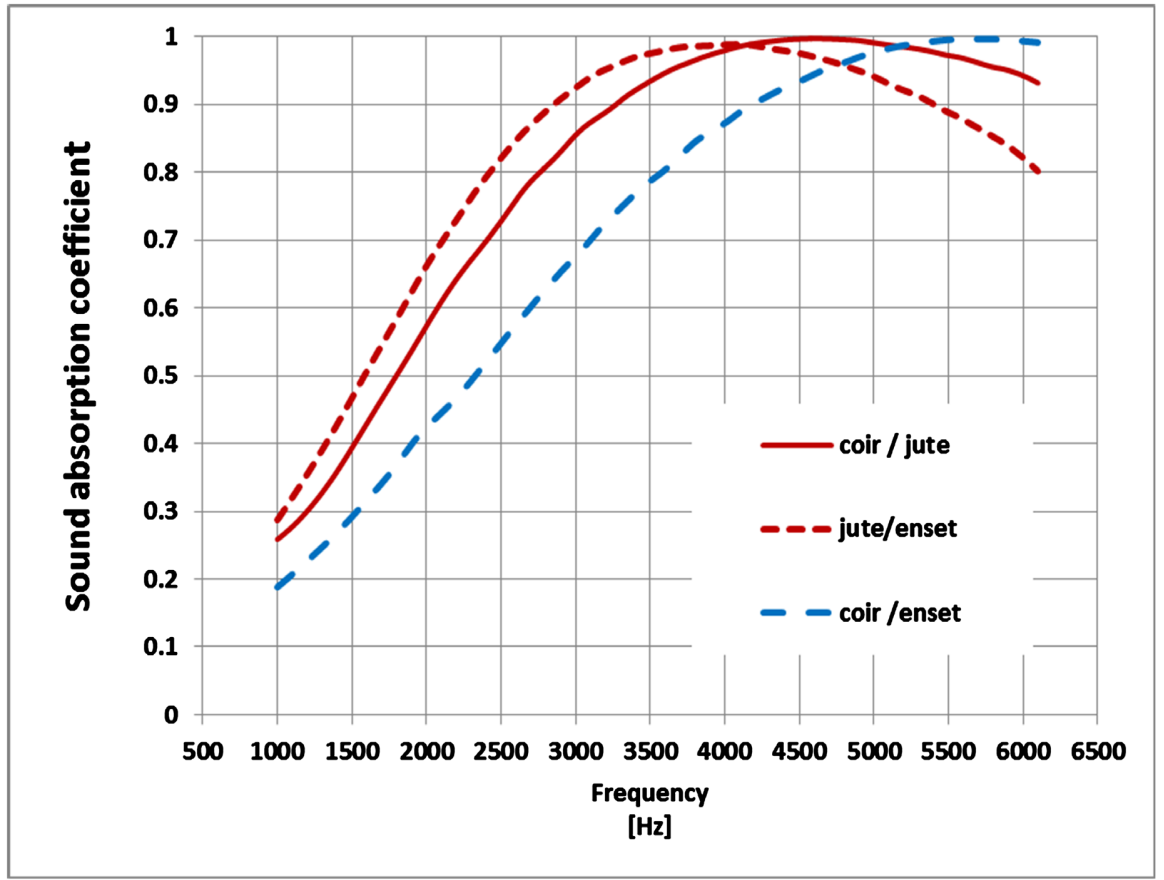

Figure 5. Acoustic properties of blended warp knitted structure coir/jute, coir/enset and jute/enset.

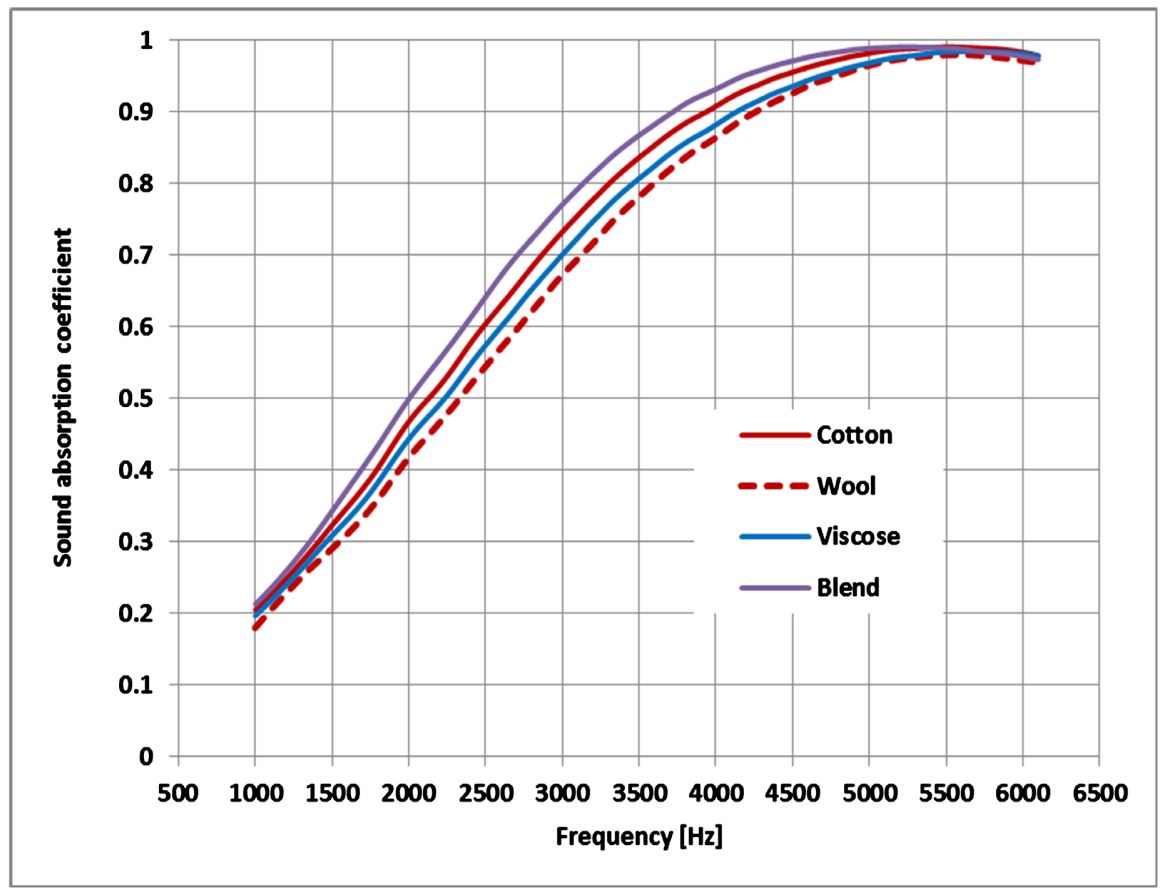

Figure 6. Acoustic properties of knitted fabric made from cotton, wool, viscose and Blended fiber.

filament yarns like viscose were effective for weft knitted fabric while only filament yarns can be effective in warp knitted fabric. It is observed that the knitted fabrics acoustic materials prepared from waste materials had a promising future as a cost-effective sound absorbs orbing material. Moreover, the test revealed 
that blended knitted fabric had a better sound absorption property. Many efforts are currently being made to limit the environmental impact of textile production: well-known brands have lately supported strategies devoted to the use of recycled materials, the reduction of solid waste, and the wastage of raw constituents; non-profit institutions have really been formed to certify companies that use pre- or post-consumer waste in their products; and, finally, scientific research has investigated the potential valorization of textile waste.

\section{Conflicts of Interest}

The authors declare no conflicts of interest regarding the publication of this paper.

\section{References}

[1] Ramakrishna, S. and Hull, D. (1991) Mechanical Properties of Knitted Fabric Composites. Proceedings of the Eighth International Conference on Composite Materials, Honolulu, 15-19 July 1991, A1-A10.

[2] Offermann, P. (1997) Biaxial Reinforced Knitted Fabrics for Composite Reinforcement. Promotional Leaflet, Technische Universität Dresden, Dresden.

[3] Ramakrishna, S. and Hull, D. (1994) Tensile Behaviour of Knitted Carbon-FibreFabric/Epoxy Laminates-Part II: Prediction of Tensile Properties. Composites Science and Technology, 50, 249-258. https://doi.org/10.1016/0266-3538(94)90146-5

[4] Andersson, C.H. and Eng, K. (1993) Split Film Based Weft Insert Warp Co-Knitting and Lost Yarn Preforming, Two New Routes for Composite Materials Preforming. Proceedings of the ECCM, 6, 237-242.

[5] Ramakrishna, S., Fujita, A., Cuong, N.K. and Hamada, H. (1995). Tensile Failure Mechanisms of Knitted Glass Fibre Fabric Reinforced Epoxy Composites. Proceedings of the Fourth Japan International SAMPE Symposium, Tokyo, 24-28 September 1995, 661-666.

[6] Ko, F.K., Krauland, K. and Scardino, F. (1982) Weft Insertion Warp Knit for Hybrid Composites. In: Hayashi, T., Kawata, K. and Umekawa, S., Eds., Proceedings of ICCM-IV, Tokyo, 25-28 October 1982, 1169-1176.

[7] Rudd, C.D., Owen, M.J. and Middleton, V. (1990) Mechanical Properties of Weft Knit Glass Fibre/Polyester Laminates. Composites Science and Technology, 39, 261-277. https://doi.org/10.1016/0266-3538(90)90045-7

[8] Phillips, D., Verpoest, I. and van Raemdonck, J. (1996) 3D-Knitted Fabrics for Sandwich Panels. Texcomp-3. 18/1.

[9] Anand, S. (1996) Warp Knitted Structures in Composites. Proceedings of the Seventh European Conference in Composite Materials, London, 14-16 May 1996, 407-413.

[10] Stumpf, H., Mader, E., Baeten, S., Pisanikovski, T., Zah, W., Eng, K., Anderson, C.H., Verpoest, I. and Schulte, K. (1996) New Thermoplastic Composite Preforms Based on Split-Film Warp-Knitting. Texcomp-3. 20/1.

[11] Wu, W.L., Kotaki, M., Fujita, A., Hamada, H., Inoda, M. and Maekawa, Z. (1993) Mechanical Properties of Warp-Knitted Fabric-Reinforced Composites. Journal of Reinforced Plastics and Composites, 12, 1096-1110. https://doi.org/10.1177/073168449301201006 
[12] Ramakrishna, S. (1997) Analysis and Modeling of Plain Knitted Fabric Reinforced Composites. Journal of Composite Materials, 31, 52-70. https://doi.org/10.1177/002199839703100104

[13] Gibbon, J. (1994) Knitting in the Third Dimension. Textile Horizons, 14, 22-25.

[14] Huang, Z.M. and Ramakrishna, S. (1999) Development of Knitted Fabric Reinforced Composite Material for Prosthetic Application. Advanced Composites Letters, 8, 289294. https://doi.org/10.1177/096369359900800603

[15] Kosuge, K., Takayasu, A. and Hori, T. (2005) Recyclable Flame Retardant Nonwoven for Sound Absorption. Journal of Materials Science, 40, 5399-5405. https://doi.org/10.1007/s10853-005-4338-9

[16] Zhou, H., Li, B., Huang, G.S. and He, J. (2007) A Novel Composite Sound Absorber with Recycled Rubber Particles. Journal of Sound and Vibration, 304, 400-406. https://doi.org/10.1016/j.jsv.2007.02.024

[17] Ersoy, S. and Küçük, H. (2009) Investigation of Industrial Tea-Leaf-Fibre Waste Material for Its Sound Absorption Properties. Marmara University, Department of Mechatronics Education, Istanbul.

[18] Mohanty, A.R. and Fatima, S. (2014) Noise Control Using Green Materials. Sound \& Vibration, 49, 13-15.

[19] Möser, M. (2004) Engineering Acoustics. Springer, New York.

[20] Zhang, J.C., et al. (2018) Sound Absorption Characterization of Natural Materials and Sandwich Structure Composites. Aerospace, 5, Article No. 75.

https://doi.org/10.3390/aerospace5030075 